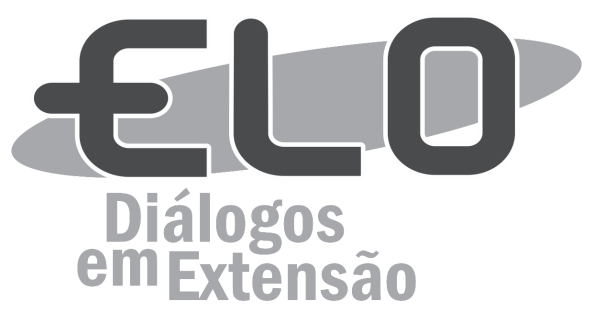

\title{
Núcleo de educação de adultos: perspectivas e desafios
}

\author{
Flávia de Castro Almeida, Amanda Daniela da Costa, Ana Paula Ramos Barbosa ${ }^{1}$
}

\begin{abstract}
Resumo: O presente trabalho teve como foco a Educação de Jovens e Adultos (EJA), sendo o objeto de estudo os principais desafios enfrentados nessa modalidade no Núcleo de Educação de Adultos (NEAD), situado na cidade de Viçosa/MG, nas dependências da Universidade Federal de Viçosa (UFV). Trata-se de um trabalho concluído durante a disciplina Fundamentos da Educação de Jovens e Adultos (EDU 263), ministrada pela professora Rosa Cristina Porcaro no ano de 2014, que tem por objetivo pesquisar os principais desafios da EJA em diferentes ambientes de ensino. Tendo em vista a grande visibilidade que essa modalidade de ensino vem adquirindo, esse estudo teve por objetivo principal identificar quais os desafios enfrentados no Núcleo para promover um ensino de qualidade a essas pessoas que, por diversos motivos, não tiveram condições de frequentar a escola em idade regular, além de resgatar as dificuldades enfrentadas desde a criação do Núcleo, relacionar os desafios enfrentados no NEAD aos desafios da EJA em âmbito geral e, por fim, identificar os caminhos traçados com intuito de amenizar ou, pelo menos, superar essas dificuldades. Como referencial teórico para embasar o estudo, foi estabelecido um diálogo entre autores estudados no decorrer da disciplina, os quais trazem uma carga de informações importante para essa área de pesquisa, tais como Porcaro, Freire, Martins, Bernardino e Soares. Os procedimentos metodológicos escolhidos para possibilitar o estudo foram, primeiramente, análise documental para coleta de dados, visitas técnicas ao NEAD e entrevistas semiestruturadas com a coordenadora pedagógica e coordenadora geral do local, além de entrevistas não estruturadas com monitoras que atuam nas salas de aula. Em geral foi possível perceber que os desafios enfrentados no Núcleo não são muito distintos dos desafios enfrentados na EJA, principalmente no que tange à evasão dos alunos e à falta de material didático próprio, com condições reais de garantir um processo de ensino-aprendizagem significativo para os educandos. O que fica claro é que, apesar de todas as adversidades, esse espaço educativo vem contribuindo com a formação integral de seus educandos, visando resgatar o direito deles à educação e possibilitar a esses a reintegração social.
\end{abstract}

Palavras-chave: Educação de Jovens e Adultos. Desafios Núcleo de Educação de Adultos.

Área Temática: Educação, Teorias e Metodologias em extensão.

\section{NUCLEUS OF ADULT EDUCATION: PERSPECTIVES AND CHALLENGES}

Abstract: This study focuses on Youth and Adult Education (EJA), with the central focus on the key challenges
facing this modality at the Adult Education Center (ADEN), located in Viçosa / MG, on the premises of the
Federal University of Viçosa (UFV). It is a work completed during the course Foundations of Education for
Youth and Adults (EDU 263), taught by Professor Rosa Cristina Porcaro n 2014, which aims to research the
key challenges of adulteducation in different learning environments. Given the high visibility that this type of
education is acquiring the study's main aim was to identify the challenges faced at the Center to promote
quality education to those people who, for various reasons, were unable to attend school in regular age, besides
rescuing the difficulties faced since the creation of the Center, relate the challenges faced in NEAD the challenges
of adult education in general scope and finally identify paths outlined aiming to minimize or at least overcome
these difficulties. As a theoretical framework to support the study, it established a dialogue between authors
studied in the course of discipline and they bring a load of important information for this area of research, such
as Porcaro, Freire Martins, and Bernardino Soares. The methodological procedures chosen to enable the study

Graduadas no curso de Licenciatura em Pedagogia pela Universidade Federal de Viçosa (UFV). amanda.daniela@ufv.br, flavia.c.almeida@ufb.br, ana.p.barbosa@ufv.br 
were first documental analysis for data collection, technical visits to the ADEN and semi-structured interviews with the educational coordinator and general local coordinator, as well as unstructured interviews with monitors working in rooms class. In general it was observed that the challenges faced at the Center are not very different from the challenges faced in EJA, especially with regard to the avoidance of students and the lack of proper teaching materials, with real conditions to ensure significant teaching-learning process for learners. What is clear is that despite all odds this educational area has been contributing to the integral education of their students, in order to retrieve the right thereof to education and facilitate their social reintegration.

Keywords: Youth and Adult Education. Challenges. Adult Education Center.

\section{Núcleo de educación para adultos: perspectivas y los desafios}

Resumen: Este estudio se centra en la Educación de Jóvenes y Adultos (EJA), con el foco central en los desafíos clave que enfrenta esta modalidad en el Centro de Educación de Adultos (ADEN), ubicado en Viçosa / MG, en las instalaciones de la Universidad Federal de Viçosa (UFV). Se trata de un trabajo realizado durante los cursos Fundamentos de la Educación para Jóvenes y Adultos (EDU 263), impartido por la profesora Rosa Cristina Porcaro n 2014, cuyo objetivo es la investigación de los principales retos de la educación de adultos en diferentes entornos de aprendizaje. Dada la alta visibilidad que este tipo de educación está adquiriendo objetivo principal del estudio fue identificar los desafíos que enfrentan en el Centro de promover una educación de calidad a aquellas personas que, por diversas razones, no pudieron asistir a la escuela en edad regular, además de rescatar las dificultades que desde la creación del Centro, se refieren a los desafíos que enfrentan en $N E A D$ los desafíos de la educación de adultos en alcance general y, finalmente, identificar los caminos señalados con el objetivo de reducir al mínimo o al menos superar estas dificultades. Como marco teórico para apoyar el estudio, se estableció un diálogo entre los autores estudiados en el curso de la disciplina y que traen una carga de información importante para esta área de investigación, tales como Porcaro, Freire Martins, y Bernardino Soares. Los procedimientos metodológicos elegidos para permitir el estudio fueron los primeros análisis documental para la recolección de datos, visitas técnicas a las entrevistas Adén y semi-estructuradas con el coordinador de educación y coordinador general local, así como entrevistas no estructuradas con monitores que trabajan en las salas clase. En general se observó que los desafíos que enfrentan en el Centro no son muy diferentes de los desafios enfrentados en EJA, especialmente con respecto a la prevención de los estudiantes y la falta de materiales didácticos adecuados, con las condiciones reales para garantizar el proceso de enseñanzaaprendizaje significativo para aprendices. Lo que está claro es que a pesar de todos los pronósticos esta área educativa ha estado contribuyendo a la formación integral de sus alumnos, con el fin de recuperar el derecho de los mismos a la educación y facilitar su reinserción social.

Palabras clave: Juventud y Educación de Adultos. Desafios. Centro de Educación de Adultos.

\section{Introdução}

O Núcleo de Educação de Adultos surgiu a partir da necessidade de investimento na alfabetização dos funcionários da Universidade Federal de Viçosa. Essa necessidade foi abordada pela primeira vez na Assembleia Geral de inauguração da Associação dos Servidores Técnico-Administrativos (ASAV) no ano de 1984, a partir da reivindicação da criação de um curso de alfabetização para os servidores da instituição, tendo em vista a grande porcentagem de funcionários analfabetos.

Um ano após essa assembleia, a Comissão de Revisão dos Planos de Cargos e Salários da UFV propôs a criação desse espaço, que ficou então dependendo apenas da autorização do Reitor para o desenvolvimento do curso, além da liberação dos funcionários para frequentá-lo. Foi então iniciado, no ano de 1987, o Projeto de Alfabetização de Adultos da UFV, sob coordenação da ASAV e com o apoio do Departamento de Educação (DPE). Primeiramente o projeto tinha por objetivo atender apenas à alfabetização, que se caracterizava como maior demanda, tendo em vista que $30 \%$ dos funcionários se caracterizavam como analfabetos absolutos ou funcionais, segundo pesquisa realizada pelo sindicato.

Em 1990 o perfil do curso apresentou uma nova configuração. A coordenação foi assumida pelo DPE e foram iniciadas pesquisas na área de EJA, realizadas pelos monitores e professores do departamento, que favoreceram a obtenção de recursos e equipamento da sede, os quais foram instalados na Vila Gianetti, no ano de 1995.

Quanto mais a demanda de alunos aumentava, a necessidade de uma escolarização mais ampla para os funcionários também crescia. Tendo isso em vista, a partir do ano 1993, o curso foi estendido 
e passou a oferecer também preparação para exames supletivos do primeiro ao quinto ano do ensino fundamental e, mais tarde, em 1995, também para os exames de suplência do sexto ao nono ano do ensino fundamental. Com essa ampliação de atendimento, o projeto passou a ser denominado Núcleo de Educação de Adultos (NEAD), e, então, deu início ao atendimento dos familiares de funcionários, passando a oferecer, também, turmas de ensino médio.

Apesar dessa ampliação no atendimento no ano de 1999, houve uma grande queda no número de alunos matriculados em razão da cobrança da instituição quanto à frequência e quanto ao desenvolvimento dos alunos. O motivo dessa cobrança vinha de que muitos dos chefes dos funcionários desacreditavam no potencial do curso por não verem compromisso dos alunos e por acreditarem que o tempo despendido para frequentar as aulas era perdido. Para superar esse desafio a Coordenadora do núcleo buscou apoio com os professores do Departamento de Educação e foram criadas as Coordenações de Área, para que cada área tivesse um professor para orientar as monitoras, tendo em um vista um melhor planejamento e desenvolvimento de suas práticas de trabalho. Também foi realizada uma campanha entre os chefes de setor da UFV para conscientizá-los sobre a importância dos estudos para seus funcionários, pois eles estavam resistindo à liberação dos servidores. Além disso, foram abertas vagas de ensino médio, pois muitos alunos haviam concluído o ensino fundamental e demandavam a continuidade dos estudos.

Já no ano seguinte o número de matrículas dobrou, sendo que todas as vagas disponíveis foram preenchidas, ficando ainda muitos alunos em uma fila de espera. De acordo com o que foi pesquisado na época, esse aumento ocorreu em função do estabelecimento de uma meta por parte do Ministério da Administração e Reforma do Estado - MARE, visando à escolarização de todos os funcionários públicos. A partir disso foi feita uma campanha por parte do NEAD com o objetivo de estabelecer uma relação de colaboração com os chefes dos funcionários para que esses os incentivassem a retomar os estudos. A partir disso foi necessária uma melhor estrutura para o núcleo, pois o aumento da demanda exigia um local capaz de acolher esse grande número de estudantes. Foi então que o núcleo foi contemplado com reformas em vistas da melhora de sua estrutura.

Desde sua criação, o NEAD enfrenta inúmeras dificuldades. Entre os desafios, os principais destacados são a permanência dos educandos no curso, a carência de professores, a falta de material didático, heterogeneidade das turmas (no sentido etário, cognitivo, o ritmo de aprendizado, por exemplo). Entretanto a coordenação, junto aos monitores, não mede esforços para buscar as melhores alternativas para superá-los, de acordo com as possibilidades.

\section{Um resgate da história da EJA no Brasil}

A Educação de jovens e adultos apresenta várias fases desde seu surgimento até os dias atuais. Tendo isso em mente, é possível afirmar que não existe apenas uma história da EJA. Pelo contrário, essa modalidade de ensino reconhecida pela legislação educacional, passou por vários acontecimentos que marcaram, de forma positiva e/ou negativa, seu trajeto até o momento.

Levando-se em consideração a história do Brasil e o modo como esse país foi colonizado, pode-se afirmar que a história da EJA se iniciou como um processo de domesticação, pois no momento em que os portugueses chegaram ao Brasil a primeira iniciativa foi a de 'educar' os índios nativos para tê-los sobre controle, ou seja, por meio da catequese, os jesuítas impunham sua doutrina religiosa, de caráter moralizador, a fim de dominar os índios e propagar a religião católica. Em função desse fato, a educação de jovens e adultos, em seu início, era muito mais religiosa do que educacional. O fato da domesticação se repetiu com os escravos negros, exceto para as mulheres que não tinham direito a qualquer tipo de educação, mesmo a mais básica.

No Brasil Império, o cenário da educação de jovens e adultos não passou por grandes mudanças desde a colonização. Nessa época, a educação para essa categoria era bastante elementar. Com a institucionalização, as elites eram instruídas em escolas de qualidade e a camada popular era "civilizada" pela elite em escolas que os preparava para servir ao mercado de trabalho, o que foi intensificado com o processo de industrialização. Com isso se tem um sistema educacional dualista. A Educação de Jovens e Adultos era vista como filantropia (PAIVA, 1987, p.121), na qual as camadas menos favorecidas eram civilizadas para servir a elite. Nesse momento, a educação se voltou para a necessidade de formar um operário educado para trabalhar nas indústrias. Mais uma vez a preocupação não era com a educação, mas sim com a necessidade de formar mão de obra, transmitindo para a educação um caráter tecnicista. 
A partir da década de 1940, com grande incentivo da UNESCO para que as nações voltassem seu olhar para a Educação, a EJA ficou a cargo de inúmeras campanhas de alfabetização. O governo brasileiro lançou a $1^{\text {a }}$ Campanha de Educação de Adultos (1947), que tinha por objetivo promover a alfabetização rápida dos adultos analfabetos do país, por meio do curso primário, com capacitação profissional. Nesse momento, em que o analfabetismo era visto como grande empecilho para desenvolvimento do Brasil e o analfabeto era visto como um incapaz, essa primeira Campanha conseguiu iniciar um processo de mudança desse pensamento, tendo como resultado uma pequena disponibilidade de atendimento aos jovens e adultos. A Campanha sofreu duras críticas por tratar o analfabetismo como algo a ser erradicado, por seu caráter missionário e assistencialista.

Em 1958, no governo de Juscelino Kubitschek, aconteceu o $1^{\circ}$ Seminário em prol da EJA, que reuniu delegações de todos os estados para discutir reformas que contribuíssem para mudar o cenário da educação de jovens e adultos. Nesse momento, a delegação de Pernambuco, que contava com a presença de Paulo Freire, se destacou trazendo uma nova concepção sobre a relação entre analfabetismo e pobreza. Para ele, a EJA deveria ser organizada de acordo com as características de seu alunado, o material deveria ser próprio para essa modalidade e, principalmente, o aluno não deveria mais ser visto como um ignorante, mas como uma pessoa capaz de produzir saberes e que tem o direito de ser educado. Se antes o analfabetismo era apontado como causador da pobreza e entrave no desenvolvimento do país, a partir das ideias de Paulo Freire, ele passou a ser visto como consequência da pobreza, gerada em decorrência das desigualdades da estrutura social.

Paulo Freire ganhou grande visibilidade a partir desse Seminário e veio a se tornar responsável por criar um Programa Nacional de Alfabetização de Adultos em 1963, encarregado pelo governo, que, nesse momento, abriu mão das campanhas de alfabetização.

As ideias de Paulo Freire se disseminaram por todo o país e, juntamente ao Plano Nacional de Alfabetização de Adultos, começaram a acontecer movimentos de educação popular que visavam à integração dos indivíduos analfabetos no âmbito socioeconômico e político da sociedade, esses movimentos viam na educação um forte instrumento de ação política. Toda essa movimentação em prol da EJA foi interrompida em 1964 pelo Golpe Militar, já que as iniciativas de instruir a população passaram a ser consideradas uma ameaça no período de ditadura. Nesse período, o único movimento que sobreviveu ao período de ditadura foi o MEB - Movimento de Educação de Base, por estar ligado à Igreja Católica.

Após o Golpe Militar, o governo voltou seu foco novamente para programas de alfabetização assistencialistas e aligeirados. Nessa perspectiva, surgiu o MOBRAL - Movimento Brasileiro de Alfabetização - que buscava oferecer uma alfabetização funcional aos jovens e adultos na faixa etária de 15 a 30 anos, ou seja, apenas tinha a intenção de dissipar técnicas básicas de leitura, escrita e cálculos. Com isso, as concepções de Paulo Freire foram abandonadas e novamente a EJA foi desvinculada do sentido crítico, reflexivo e problematizador proposto por esse educador.

No ano de 1971, a partir da Lei de Diretrizes e Bases da Educação (LDB), a educação de jovens e adultos passou a ser reconhecida como direito de cidadania. Para atender a essa demanda, o MEC criou Centros de Ensino Supletivos, que foram fortemente influenciados pelo tecnicismo, em razão das parcerias estabelecidas entre o MEC e o USAID - United States Agency for International Developmente, o que gerou uma grande evasão, além de formação rápida e superficial. Já na década de 1980, a partir da abertura política, os movimentos educacionais retornaram e o MOBRAL foi extinto. A partir disso, foi criada a Fundação Educar, que não mais iria propor e executar os projetos de alfabetização de jovens e adultos, mas sim financiar essas iniciativas.

A Constituição de 1988 foi um grande marco para a Educação de Jovens e Adultos, pois garantia a educação como um direito de todos e dever do Estado. De acordo com o artigo 208 da Constituição de 1988, "o dever do Estado com a educação será efetivado mediante a garantia de: I - ensino fundamental obrigatório e gratuito, assegurada inclusive, sua oferta gratuita para todos os que a ele não tiveram acesso na idade própria".

Nesse momento, instaurou-se um cenário de grandes contradições, pois ao mesmo tempo em que a Constituição falava em educação como um direito público e obrigatório para todos e de responsabilidade do governo, este voltava suas iniciativas para o Ensino Fundamental, tendo como foco a educação de crianças. Com a extinção da Fundação Educar, o governo se absolveu da responsabilidade de garantir a educação de jovens e adultos e a EJA ficou a cargo dos municípios. Esse 
movimento de municipalização, junto dos demais acontecimentos da época, foi segundo Haddad (2007) a grande causa da não concretização da Constituição de 88.

Com a responsabilidade da EJA passada para os municípios, ocorreram algumas experiências que resgataram o compromisso dos movimentos sociais, sob forte influência da pedagogia de Paulo Freire. Nesse período, houve grande empenho da sociedade civil em prol da EJA, com a criação de fóruns de educação, visando garantir a educação de qualidade como um direito, a inclusão de todos no contexto educacional, flexibilidade em relação às possibilidades dos alunos, formação do professorado, avaliações e aprendizado adequados e baseados nas vivências dos alunos.

A partir da década de 1990, com a nova LDB, que apesar de reconhecer a EJA como um direito, não se voltou ao problema do analfabetismo, e a Emenda Constitucional, que criou o Fundo de Valorização do Ensino Fundamental (FUNDEF) como um fundo de financiamento que não contemplou a EJA, ocorreu a limitação da possibilidade da universalização da EJA, ao passo que os investimentos se voltaram para o ensino de crianças e adolescentes. Com isso ocorreu a divisão das responsabilidades entre as esferas do governo no âmbito da educação.

Em contrapartida, em nível internacional ocorria o reconhecimento da importância da educação de jovens e adultos. Mais uma vez, a UNESCO se encarregou de mobilizar os países para investir em educação. Em 1996, foi lançado, em Natal/RN, o Programa Alfabetização Solidária como preparação para a V CONFINTEA - Conferência Internacional de Adultos, que aconteceu na Alemanha. Esse programa, assim como as campanhas, consistia em uma iniciativa aligeirada, com alfabetizadores sem preparo suficiente, o que não gerou resultados significativos. Além disso, por ter como slogan a frase "Adote um analfabeto", esse programa reafirmava a concepção de que o analfabeto era uma pessoa incapaz e dependente de assistência e não um cidadão de direitos.

Além desse programa, outras iniciativas surgiram a partir da preparação para a V CONFINTEA. O MEC criou uma Comissão Nacional de EJA, que acarretou uma mobilização dos Estados a fim de se reunirem para diagnosticar ações em função da EJA. A partir disso, iniciaram-se os encontros nacionais de EJA. O ponto de partida foi a realização de um encontro em Curitiba para a socialização dos temas abordados na V CONFINTEA. Em 1999 ocorreu o $1^{\circ}$ ENEJA - Encontro Nacional de Educação de Jovens e Adultos. Além disso, também foram organizados Fóruns Estaduais de EJA, que surgiram como nova forma de requerer direitos para a EJA.

No governo de Fernando Henrique Cardoso (1994-2002), o envolvimento do Ministério da Educação com a Educação de Jovens e Adultos foi mínimo, ficando a responsabilidade a cargo da iniciativa privada, por intermédio do Programa Alfabetização Solidária. Já no governo Lula, o primeiro a se ocupar, aparentemente, de fato com a EJA, foi criada a Secretária de Educação Continuada, Alfabetização e Diversidade (SECAD), que trouxe para o MEC a responsabilidade de atender essa modalidade de ensino, tirando dessa o caráter assistencial anteriormente imputado à EJA.

Mais recentemente no que diz respeito à EJA os fatos mais importantes foram o estabelecimento das Diretrizes para a Educação de Jovens e Adultos, estabelecidas a partir do Parecer CNE 11/2000, e a criação do FUNDEB - Fundo de Desenvolvimento da Educação Básica, que ao contrário do FUNDEF, contemplou a EJA, apesar de que o financiamento para essa categoria seja inferior ao garantido para a educação regular. Ainda na forma de campanha, foi criado, também no governo Lula, o Programa Brasil Alfabetizado, além do PROEJA - Programa Nacional de Integração Profissional com a Educação Básica na modalidade de Educação de Jovens e Adultos e o PROJOVEM - Programa Nacional de Inclusão de Jovens, que tinham como objetivo formação inicial continuada e educação profissional técnica a nível médio, declarando direito de todos os jovens e adultos à alfabetização de qualidade.

Tendo em vista toda a trajetória da EJA, pode-se dizer, felizmente, que houve um avanço desde o seu surgimento até os dias atuais, tendo em vista principalmente o reconhecimento que essa modalidade ganhou em todo país, embora ainda haja muitos desafios a serem superados em prol de uma educação de jovens e adultos de qualidade, como por exemplo, investimento na formação de professores, falta de continuidade dos estudos, que ocasiona a conversão dos analfabetos em analfabetos regressivos e o fim do ensino aligeirado visando quantidade, sem se preocupar com a aprendizagem significativa dos alunos, tendo em vista que a ineficiência do ensino emergencial, com prazos limitados, já foi comprovada.

Nesse sentido a Educação de Jovens e Adultos ainda tem muito que avançar, de modo que garanta a seus alunos não apenas um certificado que de nada vale se este tiver lhes proporcionado um aprendizado meramente técnico, ou ainda um aprendizado que não se efetiva na prática; mas sim que garanta a seu alunado uma consciência crítica que lhes permita se inserir na vida social de forma ativa como cidadãos de direito que são. 


\title{
Objetivos
}

A pesquisa que nos propomos a realizar consiste em identificar os principais desafios enfrentados para a educação de jovens e adultos no Núcleo de Educação de Adultos (NEAD) da Universidade Federal de Viçosa (UFV). Mais especificamente, objetivamos:

- Resgatar as dificuldades enfrentadas desde a criação do Núcleo.

- Relacionar os desafios enfrentados no NEAD aos desafios de âmbito geral da EJA.

- Identificar os caminhos que a coordenação e educadores (as) percorrem para amenizar ou superar esses desafios.

\section{Metodologia}

Neste trabalho, no qual foram investigados os principais desafios enfrentados para a educação de jovens e adultos no NEAD, com foco nas dificuldades enfrentadas desde sua criação, na relação entre essas dificuldades e as adversidades da EJA de modo geral, além dos caminhos buscados para superálas, optamos por uma metodologia qualitativa, por não estarmos preocupadas com a representatividade quantitativa dos dados, mas sim com seu caráter significativo para compreender o fenômeno em questão. Tendo em vista que objetivo principal é de investigar e não de quantificar acreditamos que essa perspectiva seja a mais indicada.

Conforme Minayo (1994, p. 21):

\begin{abstract}
A pesquisa qualitativa responde a questões muito particulares. Preocupa-se com um nível de realidade que não pode ser quantificado. Ou seja, ela trabalha com um universo de significados, motivações, aspirações, crenças, valores e atitudes, o que corresponde a um espaço mais profundo das relações, dos processos e dos fenômenos que não podem ser reduzidos à operacionalização de variáveis.
\end{abstract}

Araújo e Borba (2004, p. 40) evidenciam que "[...] quando decidimos desenvolver uma pesquisa, partimos de uma inquietação inicial e, com algum planejamento, não muito rígido, desencadeamos um processo de busca". Assim sendo nossa busca pela coleta de dados foi primeiramente baseada em uma análise documental, com o objetivo de resgatar os desafios enfrentados desde a criação do núcleo até os dias atuais, com vistas a estabelecer uma relação entre esses e os desafios da EJA em âmbito geral.

De acordo com Luna (1999), essa coleta de dados possibilita um apanhado geral sobre os principais trabalhos desenvolvidos sobre determinado assunto sendo, portanto fonte de dados relevantes para novos estudos. Foram realizadas visitas técnicas ao núcleo, a fim de também serem feitas análises de documentos oficiais, para Monezi $(2005$, p.3) a visita técnica possibilita uma aprendizagem muito significativa, pois permite ao aluno, além de ver e ouvir, sentir na prática a organização do espaço visitado, tornando o processo mais motivador para a aprendizagem.

Por fim foram feitas entrevistas semi-estruturadas com a coordenadora pedagógica e coordenadora geral do local, além de entrevistas não estruturadas com algumas monitoras que atuam nas salas de aulas.

De acordo com Lakatos (1996, p. 37), a entrevista:

[...] é uma das etapas mais importantes da pesquisa, exigindo tempo e cuidados. Entre eles o planejamento da entrevista, que deve ter em vista o objetivo a ser alcançado; a escolha do entrevistado, que deve ser alguém que tenha familiaridade com o tema pesquisado.

Os dados coletados foram registrados e analisados com o objetivo de identificar quais ações (caminhos) têm sido tomadas para superar ou, ao menos, amenizar essas dificuldades encontradas.

A partir da análise e estudos dos dados buscamos identificar pontos importantes que trouxeram respostas aos objetivos propostos e subsidiaram a realização deste trabalho. 


\title{
Contexto da pesquisa
}

O presente trabalho foi desenvolvido no Núcleo de Educação de Adultos (NEAd), localizado na Vila Gianetti, casa de número 33, na Universidade Federal de Viçosa (UFV).

O local foi escolhido por ser um dos temas do trabalho final da disciplina Fundamentos da Educação de Jovens e Adultos (EDU263), ministrada pela Professora Doutora Rosa Cristina Porcaro, que também é coordenadora do núcleo. O trabalho teve por finalidade identificar os desafios da EJA em diferentes instituições de ensino, sendo o NEAd uma delas.

Os sujeitos que contribuíram para esse trabalho foram três monitoras do NEAd, a coordenadora pedagógica Maria Dalva de Freitas e a supracitada coordenadora Rosa. Esses sujeitos foram escolhidos tendo em vista os objetivos do trabalho em identificar os desafios enfrentados no NEAd no processo de ensino/aprendizagem de alunos adultos.

\section{Análise dos dados}

Análise dos dados é a atividade de transformar um conjunto de informações com o objetivo de poder verificá-las melhor, dando-lhes ao mesmo tempo uma razão de ser e uma análise racional. Essa fase da pesquisa foi o momento de organizar os dados, agrupá-los e interpretá-los para fundamentar tudo que será apresentado como resultado deste trabalho.

Primeiramente foram trabalhadas as informações referentes às repostas dadas pelas monitoras do NEAd à entrevista não estruturada realizada com essas. De acordo com Gil (1999, p. 117):

\begin{abstract}
As entrevistas não estruturadas são radicalmente opostas às entrevistas estruturadas. $\mathrm{O}$ entrevistador não possui um conjunto especificado de questões e nem as questões são perguntadas numa ordem específica. O entrevistador possui grande liberdade de ação e pode incursionar por vários assuntos e testar várias hipóteses durante o curso da entrevista.
\end{abstract}

Foram ouvidas três monitoras, sendo a primeira professora de Português do primeiro segmento do Ensino Fundamental, a segunda professora do curso de Inclusão Digital e a terceira professora de Física no Ensino Médio.

A partir das respostas dadas, o maior desafio identificado foi referente à falta de material didático específico da EJA. Na fala de todas as monitoras, foi citada a dificuldade em adequar materiais existentes à realidade de seus alunos. Além de terem de planejar as aulas, elas precisam ainda pesquisar as atividades, para depois adequá-las da melhor maneira possível ao alunado.

Essa dificuldade fica clara na fala da professora de Português que relatou:

[...] a maioria das atividades são voltadas para a Educação Infantil, não há uma atividade específica para EJA, então esse é o meu maior desafio em relação ao meu trabalho, a questão do material didático. Eu nunca encontrei uma atividade que eu pudesse falar "essa aqui está totalmente de acordo pra eu usar com meus alunos", sempre tenho que procurar e modificar. (Monitora de Português)

A esse respeito uma situação que merece destaque foi relatada pela professora do curso de Inclusão Digital, que ao iniciar seu trabalho no NEAd tinha em mãos um planejamento de aulas, baseado em um material que ela pesquisou, com objetivo de trabalhar com os alunos o acesso à internet, digitação, manuseio de programas antivírus, por exemplo, no entanto ao chegar à sala ela se deparou com alunos que não conseguiam ler os comandos no computador, mal sabiam digitar e que não tinham domínio do mouse. Segundo ela essa foi uma grande frustração, pois tudo o que havia sido planejado não tinha condições de ser consolidado.

Diante desse percalço na segunda aula ela optou por conversar com os alunos da turma para poder identificar o que eles esperavam das aulas e quais conhecimentos eles já tinham sobre inclusão digital, para, então, usá-los como ponto de partida podendo assim trabalhar de acordo com a realidade de seus alunos.

Ainda em relação ao material didático a monitora de Física relatou que a maioria de seus alunos chega à sala sem domínio matemático prévio, necessário para que aprendam Física e, por isso, ela 
precisa adaptar suas atividades duas vezes: uma vez para inserir os conceitos matemáticos necessários e uma segunda para adequá-la aos alunos adultos.

Para além dos desafios com os materiais didáticos a monitora da Inclusão Digital também relatou dificuldade com relação à carga horária das monitoras. Segundo ela todas as monitoras precisam cumprir duas horas diárias nos cinco dias úteis da semana, o que gera certa dificuldade em relação à permanência dessas no núcleo.

De acordo com a fala dela essa carga horária muitas vezes impede a participação em eventos acadêmicos, que podem valorizar seus currículos enquanto discentes, o que muitas vezes levam algumas pessoas a abrirem mão do trabalho no NEAd para investir na carreira universitária, de forma que isso acarreta em uma troca constante de monitoras, refletindo no desempenho dos alunos, já que esses alunos, na maioria das vezes, atribuem seu sucesso à figura do(a) professor(a); logo, se muda o professor, eles se sentem frustrados e em alguns casos chegam a evadir do curso.

Sobre a imagem que os alunos têm a respeito do professor, Barreto e Barreto (2008, p. 64) explicam que os alunos da EJA “[...] imaginam que o professor é o único detentor do conhecimento que vão buscar, acham que devem prestar total atenção naquilo que o professor diz (...), na opinião dos alunos o conhecimento vem do professor".

Aprofundando o assunto da evasão, identificado como maior desafio da EJA de modo geral, as monitoras de Física e Inclusão Digital tiveram falas opostas à da monitora de Português. Enquanto a monitora de Português relatou que seus alunos sempre estão presentes na aula, inclusive chegam antes dela na sala e sempre justificam as faltas, nas raras vezes em que isso acontece, as monitoras de Física e de Inclusão Digital destacaram a evasão como um grande problema.

De acordo com o foi dito, a grande causa dessa evasão é o fato de os alunos sentirem muita dificuldade para acompanhar as aulas e não verem um retorno tão breve como esperam em seu aprendizado. A monitora de Inclusão Digital relatou:

[...] quando eles começam a faltar muito, a gente liga pra descobrir o motivo e, de início, eles dizem que estão muito ocupados, que não conseguem mais conciliar o trabalho e o estudo, porém depois de muita insistência eles acabam dizendo que não querem vir mais porque estão achando as aulas muito difíceis e que não conseguem acompanhar a turma e a professora. (Monitora de Inclusão Digital)

Os dois desafios relatados pelas monitoras (material didático e evasão) não são específicos do NEAd, como citado acima. A evasão é hoje o maior desafio da EJA, bem como a falta de um material pensando especificamente para essa modalidade de ensino.

Posteriormente à análise das falas das monitoras foi estabelecida uma relação entre as falas das coordenadoras geral e pedagógica. A professora Rosa Cristina Porcaro está na coordenação do NEAd desde março de 1997, tendo se ausentado no período entre os anos de 2007 e 2010 para cursar doutorado, retornando em 2011.

De acordo com os relatos das coordenadoras Rosa e Maria Dalva, o NEAd hoje conta com onze monitores, que recebem capacitação no cotidiano do núcleo, por meio de sua própria vivência em sala de aula, pela participação em grupos de estudos e reuniões pedagógicas semanais, além dos conselhos de classe mensais e em fóruns de EJA. sendo que essa capacitação é coordenada pela Dalva. Em relação ao Projeto Político Pedagógico (PPP), ele foi construído pela equipe do NEAd - monitoras, pedagoga e coordenadora geral. Segundo a coordenadora Rosa foram feitas inúmeras reuniões para a discussão desse. As aulas no núcleo acontecem de segunda a sexta-feira e tem duração de duas horas diárias, sendo os alunos divididos em salas de acordo com seu nível de aprendizado e de forma que melhor atenda às necessidades e expectativas do alunado.

Mais uma vez a evasão foi apontada, a coordenadora pedagógica Maria Dalva de Freitas afirmou que seu maior desafio é a desistência por parte dos alunos. A coordenadora Rosa apontou também como desafio o revezamento dos monitores (estagiários), segundo ela "quando estão prontos para o trabalho, os monitores se formam ou deixam o trabalho por se envolverem com outros". Além disso, ela relatou que a falta de autonomia para promover certificação para os educandos também é uma dificuldade, pois gera uma dependência do CESEC, que impossibilita a produção de um modelo pedagógico próprio para o segundo segmento do Ensino Fundamental. 
Para além desses desafios já relatados pelas monitoras e coordenadora pedagógica, a coordenadora Rosa também identificou desafios relacionados ao funcionamento do NEAd.

Segundo ela o núcleo não tem recursos próprios para desenvolvimento de seu trabalho, mas conta com apoio da Reitoria, Pró-reitoria de Ensino, ASAV e Departamento de Educação (DPE), que cedem respectivamente, autorização para funcionamento da sede na Vila Gianetti e manutenção dessa, onze bolsas para monitores, sendo nove cedidas pela Pró-reitoria e duas pela ASAV, três funcionários que atuam no núcleo (um contínuo, um secretário e uma pedagoga) e material de consumo. De acordo com fala da própria coordenadora Rosa, para manter a sede em funcionamento o núcleo conta apenas com esses apoios “No mais, é na coragem e na fé!".

Em relação à comparação estabelecida entre os desafios encontrados no NEAd e os desafios da EJA em âmbito geral, foi possível perceber que o núcleo, felizmente, não enfrenta determinadas dificuldades, que fazem parte dessa modalidade de ensino como, por exemplo, a juvenilização, o que provavelmente é uma consequência do modo como o núcleo surgiu, tendo a intenção de alfabetizar os servidores da Universidade, ou seja, adultos.

Outra dificuldade que não foi identificada no núcleo é o trabalho de conteúdos distantes da realidade dos alunos, pelo contrário, o trabalho é realizado com base nos pressupostos do método de Paulo Freire, que se baseiam muito no aprendizado a partir daquilo com que o aluno está familiarizado, que faça parte do seu mudo. Em uma crítica às cartilhas usadas na alfabetização de adultos, Paulo Freire expressa que "Não basta saber ler que Eva viu a uva. É preciso compreender qual a posição que Eva ocupa no seu contexto social, quem trabalha para produzir a uva e quem lucra com esse trabalho." O ensino meramente técnico, baseado em assuntos completamente fora do contexto do aluno não lhe garante aprendizado.

Por fim, mas não menos importante, o NEAd também não tem o desafio de desenvolver seu trabalho sem um coordenador com formação em EJA. A coordenadora do núcleo, Rosa Porcaro, possui Doutorado em Educação pela Universidade Federal de Minas Gerais (2011), com foco em formação de educadores de jovens e adultos e já se dedica ao NEAd há mais de quinze anos.

A partir das visitas feitas ao núcleo e pelas entrevistas realizadas, foi possível notar que o NEAd se apresenta para os alunos como um lugar acolhedor onde eles terão a oportunidade de darem continuidade - ou mesmo de iniciarem - seus estudos com vistas a se firmarem como sujeitos ativos e constituintes da sociedade em que vivem.

Sobre isso SOARES (1998, p. 100) diz que

[...] uma proposta pedagógica da EJA deve colocar-se a serviço de um projeto de construção de um novo homem, de uma nova sociedade, utilizando-as para a concretização de uma pedagogia, que é do "oprimido", mas também é da esperança.

\section{Considerações finais}

A partir da análise de todas as informações que foram coletadas para fundamentar o presente trabalho, ficou evidente a importância da ação do Núcleo de Educação de Adultos (NEAd) na busca pela garantia do direito à educação para aqueles que não puderam completar seus estudos em idade regular.

Da sessão de revisão bibliográfica, podemos concluir que os desafios da EJA não se apresentam apenas para os alunos, mas também para os docentes e em seu funcionamento de modo geral. No caso do NEAd, em particular, sua própria criação partiu de uma dificuldade: grande percentual de funcionários analfabetos em uma instituição de ensino superior federal. Em função disso, o trabalho na EJA precisa estar muito voltado para a superação desses desafios, de modo que as dificuldades não sejam um empecilho na busca dos alunos jovens e adultos pelo seu direito a uma educação gratuita e de qualidade, conforme previsto na Lei de Diretrizes e Bases da Educação Nacional (LDB 9394/96), em seu artigo $3^{\circ} \S 6^{\circ}$ e $10^{\circ}$.

Das entrevistas e visitas técnicas que foram realizadas, percebemos que o Núcleo de Educação de Adultos, por ter surgido da iniciativa de alfabetizar os servidores da UFV e por manter-se até os dias atuais investindo em oferecer educação de qualidade aos seus alunos, apresenta-se como uma grande oportunidade para todos aqueles que não puderam ou não tiveram chance de acesso em idade regular. Ainda que o núcleo passe por diversos desafios, todas as pessoas lá envolvidas estão sempre em busca 
de caminhos para superá-los, promovendo autonomia e liberdade de seus educandos enquanto sujeitos sócio-históricos que aprendem a ler e escrever para dizer sua própria palavra, revelando aos outros e a si mesmo o seu protagonismo social (FREIRE, 2005). Além disso, o núcleo vem possibilitando que a oportunidade desses alunos em retornar ao estudo seja cada vez mais válida e significativa para eles e, consequentemente, para os monitores/professores, pois só é capaz de ensinar aquele que também é capaz de aprender.

\section{Referências}

ALMEIDA, F. C. A educação de jovens e adultos no Brasil: Perspectivas e desafios. Viçosa/MG. 2014.

ARAÚJO, J. L.; BORBA, M. C. Construindo Pesquisas Coletivamente em Educação Matemática. In.: BORBA, M. C.; ARAUJO, J. L. (Org) Pesquisa Qualitativa em Educação Matemática. Belo Horizonte: Autêntica, 2004.

BARRETO, J. C.; BARRETO, V. Um sonho que não serve ao sonhador. In: Construção coletiva: contribuições à educação de jovens e adultos. Brasília: Unesco. 2008.

BERNARDES, T. A. e SILVA, E.M.V. dos A. O perfil do educando no núcleo de educação de adultos da UFV. In: XVII Simpósio de Iniciação Científica/UFV, 2007, Viçosa. XVII Simpósio de Iniciação Científica/UFV, 2007.

BERNARDINO, A. J. Concepção de Cultura Trabalho e Tempo dos Professores da Eja. Dissertação (Programa de Pós-Graduação em Educação). Centro de Tecnologia e Ciências Humanas, Pontifícia Universidade Católica, Curitiba, Paraná, 2008.

BRASIL. Constituição (1988). Constituição da República Federativa do Brasil. Brasília, DF: Senado Federal. Lei de Diretrizes e Bases da Educação Nacional. Lei número 9394, 20 de dezembro de 1996.

FÁVERO, Osmar. PIVERO, José. Educação de Jovens e Adultos na América Latina: direito e desafio de todos. São Paulo: Ed. Moderna, 2009.

FREIRE, Paulo. Conscientização: Teoria e prática. São Paulo: Cortez \& Moraes, 1980. 102p.

Educação como prática de liberdade: a sociedade brasileira em transição. Rio de Janeiro, Paz e Terra, 1981.

Pedagogia do Oprimido. $47^{\mathrm{a}}$ ed. Rio de Janeiro. Paz e Terra, 2005.

GALVÃO, Ana Maria de Oliveira; SOARES, Leôncio José Gomes. História da alfabetização de adultos no Brasil. In: ALBUQUERQUE, Eliane Borges Correia de; LEAL, Telma Ferraz. Alfabetização de jovens e adultos: em uma perspectiva de letramento. Belo Horizonte: Autêntica, 2004, p. 27-58.

GIL, A. C. Métodos e técnicas de pesquisa social. 5.ed. São Paulo: Atlas, 1999.

HADDAD, Sérgio (org.). Novos caminhos em educação de jovens e adultos - EJA: um estudo de ações do poder público em cidades de regiões metropolitanas brasileiras. São Paulo: Ed. Global, 2007.

LAKATOS, E. M.; MARCONI, M. de A. Técnicas de Pesquisa. 3.ed. São Paulo: Atlas, 1996.

LUNA, S. V. Planejamento de pesquisa: uma introdução. 2. ed. São Paulo: EDUC, 1999.

MARTINS, Rita de Cássia. A educação de jovens e adultos no município de Viçosa: Realidade, desafios e caminhos. 69f. Trabalho de conclusão de curso (Licenciatura em Pedagogia). Universidade Federal de Viçosa, Viçosa/MG, 2013.

MINAYO, M. C. S. (Org.). Pesquisa social: teoria, método e criatividade (16 ${ }^{\mathrm{a}}$ Ed) Petrópolis: Vozes. 1994.

MONEZI, C. A. A visita técnica como recurso metodológico aplicado ao curso de engenharia. Campina Grande/PB. 2005.

PAIVA, Vanilda Pereira. Educação Popular e Educação de Adultos. $5^{\circ}$ Ed. São Paulo: Loyola, Ibrades, 1987.

PORCARO, Rosa Cristina. A História da Educação de Jovens e Adultos no Brasil. Universidade Federal de Viçosa, 2004. 
Rosa Cristina. O contexto histórico da EJA no Brasil. Viçosa, MG. 2011.

SOARES, Magda Becker. Paulo Freire e a alfabetização: muito além de um método. Revista Presença pedagógica, v.4, n.21, mai/jun. 1998. P. 98-104.

SOBREIRA, R. C. de F. NEAd- Espaço Educativo de Formação e Constituição de Saberes. Disponível em: <http://meuartigo.brasilescola.com/educacao/nead.htm>. Viçosa/MG. 2008. Acesso em: $1^{\circ}$ dez. 2014.

\begin{abstract}
Anexo
Roteiro usado nas entrevistas semiestruturadas com coordenadoras do Núcleo de Educação de Adultos (NEAd).

\section{Entrevistada: Maria Dalva de Freitas.}

1) Para você, na sua função de coordenadora pedagógica, qual o maior desafio enfrentado?

2) Atualmente o NEAd conta com quantos monitores? Todos são bolsistas?

3) Como os alunos são distribuídos nas salas? Há algum critério ou é por ordem de matrícula?

4) Qual a duração das aulas? Quantos dias da semana? Há intervalo entre as aulas?
\end{abstract}

\title{
Entrevistada: Rosa Cristina Porcaro.
}

1) Há quanto tempo a senhora é coordenadora e quais os principais desafios enfrentados pela senhora desde seu ingresso no NEAD?

2) Quais são os recursos que o núcleo tem para se manter em funcionamento?

3) Em relação à capacitação das monitoras, como é feita e por quem?

4) Sobre a formulação do Projeto Político Pedagógico, quem faz e como faz?

5) Por fim, sobre a queda significativa de matrículas ocorrida em 1999, a senhora já era coordenadora do núcleo? Se sim, essa queda de alguma maneira ameaçou o trabalho do núcleo e/ou sua existência? 